\title{
Sports Medicine Australia and \\ COVID-19: providing 'virtual' support to the sports community
}

\author{
Andrea Britt Mosler (i) ,' Liam Richard West (i) ${ }^{2}$
}

The COVID-19 pandemic has sent shockwaves through the global sporting world with events and competitions postponed or cancelled. The impact on elite athletes, sporting organisations, people working in sport, and community-level sport has been extraordinary. While Sports Medicine Australia (SMA) has similarly faced considerable challenges, opportunities for the organisation to adapt and redirect its focus have presented as a result of the pandemic.

\section{SMA EDUCATION GOES ONLINE}

The cancellation of the 2020 annual SMA Conference was a difficult, but essential decision as the health and welfare of attendees was prioritised. The next annual conference will be held in Melbourne in October 2021, with dates soon to be confirmed. Additionally, all face-to-face service and education delivery was suspended during the lockdown empowering SMA to explore online professional development options.

At the commencement of the COVID-19 shutdown, SMA recognised the need to support and provide opportunities for engagement within the sports community. SMA has provided freely accessible, high quality online education content through pre-recorded Webinars (https:// bit.ly/2M9RMUs), live Webinars (https:// bit.ly/2XFe0Dd), podcasts (https://bit.ly/ 2TOmVRs) and staying healthy at home resources (https://bit.ly/3ch2Nhf).

An engaged online community of sports science and medicine professionals, coaches, athletes, and lay people with an interest in sport have been accessing this online content which will only enhance future sporting team support. Excellent multidisciplinary communication, interaction and networking has occurred through this online connection between professionals, and our rural and remote practitioners have

'La Trobe Sport and Exercise Medicine Research Centre, La Trobe University College of Science Health and Engineering, Bundoora, Victoria, Australia

${ }^{2}$ Alphington Sports Medicine Clinic, Northcote, Victoria, Australia

Correspondence to Dr Andrea Britt Mosler, La Trobe Sport and Exercise Medicine Research Centre, La Trobe University College of Science Health and Engineering, Bundoora VIC 3086, Australia; abmosler@hotmail.com
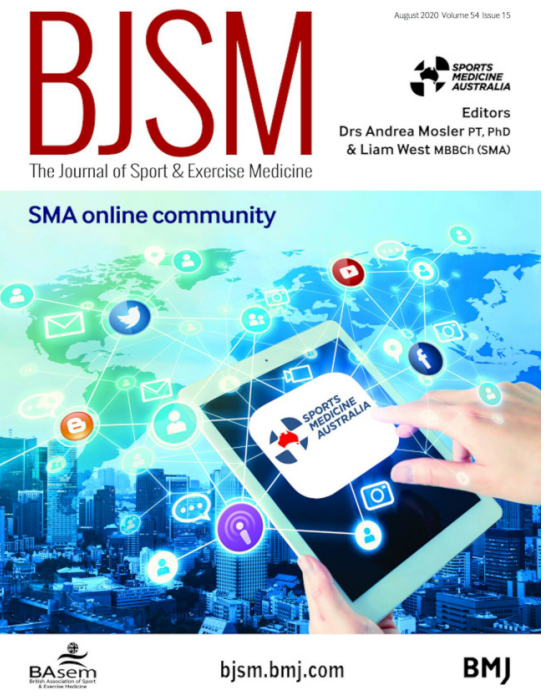

had greater opportunities to access quality professional development.

\section{TEAM BEHIND THE TEAM}

The role of support staff (especially sports trainers) will be essential for sport to resume smoothly and safely. Sports trainer accreditations have been extended by 6 months and courses now include extended online content (with class discussion) and a shorter face-to-face practical assessment. This ensures greater efficiency and continuity of training and increased access to these courses, while minimising contact time between participants in line with government recommendations to minimise the spread of COVID-19. Support staff will all need training in following the recommended frameworks such as; the use of personal protective equipment, recognising symptoms, hand hygiene and minimising personal contact or sharing of equipment while performing their essential sports medicine duties.

\section{SMA'S ROLE IN RETURNING TO COMMUNITY SPORT}

SMA is playing a vital role by providing expert advice, position statements and education material to assist the smooth resumption of sporting competitions, while minimising the risk of COVID-19 transmission. The expectations regarding social distancing, hygiene, infection control and how to safely undertake physical contact will largely fall under the responsibility of sport trainers and sports medicine personnel, with essential guidance and support provided by SMA. The recently formed SMA community sport medical advisory committee will advise on policy and guidelines for practice standards for sporting clubs and support staff. Risk management for education provision, and new education content has been developed to enhance knowledge and skills in infection control. SMA will facilitate the correct interpretation of the guidelines and adapt them as needed for the community level. Ongoing communication and support will be provided to sporting clubs and trainers at all levels through the SMA hub of resources and advice (https://bit.ly/SMACOVID).

\section{WHAT'S IN THE SPOTLIGHT OF THIS SMA ISSUE OF BJSM?}

As global lockdown restrictions are easing and individuals resume their pre-COVID duties, will running paths and tracks begin to empty? Melbourne's Associate Professor Željko Pedišić and colleagues (see page 898) have performed a systemic review and meta-analysis examining whether running is associated with a lower risk of all-cause, cardiovascular and cancer mortality, and whether the dose is important-with appropriate social distancing of course! Unquestionably, many may prefer to walk.

Sydney's physiotherapy research legend Cathie Sherrington and colleagues' (see page 885). Cochrane systematic review heralds the benefits of exercise for preventing falls in older people living in the community. As governments permit larger group gatherings, it will be important to restart community group exercise classes for the elderly. What about those individuals who are required to stay at home, perhaps under an isolation order, how should they stay active? Valentin Benzing (see page 930) from Bern, shares his $\mathrm{PhD}$ academy award-nominated work demonstrating that exergaming was a successful physical activity intervention to benefit children with ADHD. Perhaps exergaming could be an answer to physical activity while in isolation!

Twitter Andrea Britt Mosler @AndreaBMosler and Liam Richard West @Liam_West

Contributors ABM and LRW contributed equally to the writing of this manuscript.

Funding The authors have not declared a specific grant for this research from any funding agency in the public, commercial or not-for-profit sectors.

Competing interests None declared. 


\section{Warm up}

Patient consent for publication Not required.

Provenance and peer review Commissioned; internally peer reviewed.

This article is made freely available for use in accordance with BMJ's website terms and conditions for the duration of the covid-19 pandemic or until otherwise determined by BMJ. You may use, download and print the article for any lawful, non-commercial purpose (including text and data mining) provided that all copyright notices and trade marks are retained.

(c) Author(s) (or their employer(s)) 2020. No commercial re-use. See rights and permissions. Published by BMJ.

\section{(D) Check for updates}

To cite Mosler AB, West LR. Br J Sports Med 2020;54:881-882.
Accepted 4 June 2020

Br J Sports Med 2020:54:881-882

doi:10.1136/bjsports-2020-102799

\section{ORCID iDs}

Andrea Britt Mosler http://orcid.org/0000-0001-73532583

Liam Richard West http://orcid.org/0000-0002-60461613 